\title{
EL PAPEL DEL CURRÍCULO EN LA REPRODUCCIÓN DE DESIGUALDADES ÉTNICO-RACIALES. UNA MIRADA AL CASO ARGENTINO EN
} PERSPECTIVA LATINOAMERICANA

The role of the curriculum in the reproduction of ethnic-racial inequalities. A look at the Argentine case from a Latin American perspective

Mi casa es un gran barco Que no desea emprender su travesía Sus mástiles, sus jarcias, se tornaron raíces y medusas plantadas en medio de la mar; a estas alturas Nancy Morejón (2003, p. 290). ANNY OCORÓ LOANGO* Flacso-Universidad Nacional de Tres de Febrero (Argentina) annyocoro@hotmail.com

\section{RESUMEN:}

Este artículo es un ensayo que describe cómo, en América Latina, el currículo escolar ha difundido una visión eurocéntrica que, a través de la negación y el avasallamiento y de las culturas no hegemónicas, ha contribuido a

\footnotetext{
* Doctora en Ciencias Sociales de la Facultad Latinoamericana de Ciencias Sociales (FLACSO - Argentina). Docente e Investigadora Flacso- UNTREF. Integrante del equipo de investigación del Programa Educación Superior y Pueblos Indígenas y Afrodescendientes en América Latina (ESIAL) de la Universidad Nacional de Tres de Febrero (UNTREF). Presidenta de la Asociación de Investigadores Afrolatinoamericanos y del Caribe (AINALC). ORCID ID: https://orcid.org/0000-0001-5814-2368
} 


\section{Anny Ocoró Loango}

sostener las desigualdades étnico-raciales, la exclusión y el racismo epistémico presentes en nuestras sociedades. Señala que el currículo no es un elemento neutro y, haciendo foco en el caso argentino, destaca cómo el proceso de selección de contenidos, conocimientos, valores e ideologías que este condensa, ha reafirmado las posturas que excluyen la diversidad étnica y refuerzan los relatos homogéneos sobre la sociedad. Al mismo tiempo, muestra cómo hoy las luchas por el control del currículo escolar -lejos de haber desaparecido- tienen lugar a través de distintos actores que buscan moldearlo de acuerdo a sus intereses. Finalmente, se interroga sobre los desafíos que en la actualidad plantea el desarrollo de un currículo escolar plural e intercultural, capaz de dialogar con los enormes problemas que enfrenta América Latina, y de aportar herramientas para un mundo que cambia con gran celeridad.

Palabras clave: currículo; desigualdades étnico-raciales; afroargentinos/as; eurocentrismo; diversidad cultural.

\section{ABSTRACT}

This article describes how the school curriculum in Latin America has been consolidated from a Eurocentric vision that, through denial and submission and non-hegemonic cultures, has contributed to sustaining ethnic-racial inequalities, exclusion and epistemic racism present in our societies. It is an essay that states that the curriculum is not a neutral element. The Argentine case describes how the process of selection of content, knowledge, values and ideologies that condenses the curriculum, has reaffirmed the positions that exclude ethnic diversity and reinforce the idea of a supposed homogeneous society. At the same time, it shows that today the struggles for control of the curriculum are far from disappearing. They continue through different actors who seek to shape it according to their interests. Finally, the article raises the question about the challenges currently posed by the development of a plural and intercultural school curriculum, capable of dialoguing with the enormous problems facing Latin America and of providing tools for a rapidly evolving world.

42 | INTEREDU № 4 VOL. I (JuLIO 2021) PÁGs. 41-68. ISSN: 2735-6523 
Key words: curriculum; ethnic-racial inequalities; Afro-Argentines; Eurocentrism; cultural diversity.

CURRÍCULO Y DIVERSIDAD CULTURAL: UN ESPACIO DE LUCHA EN AMÉRICA LATINA

La escuela desempeñó un importantísimo rol en la consolidación de los proyectos de nación de los estados latinoamericanos. Desde ella se instrumentó la unificación de valores e ideologías que servirían para moldear las identidades nacionales. En América Latina, la escuela moderna emergió en las últimas décadas del siglo XVIII como una institución de gran importancia, entramada con la historia de la ilustración y la modernidad (Finocchio, 2012). Surge de un contexto histórico que privilegiaba la homogenización cultural para lograr la adecuación al orden social. Es mediante el currículo que se han transmitido y reforzado los imaginarios de la nación y los valores promovidos por los sectores dominantes, contribuyendo a que estos sean aceptados y legitimados. En esa conformación de nación imaginada por las elites, la voz de los grupos menos favorecidos fue silenciada en el currículo escolar (Young, 2010).

En la década del setenta, los clásicos aportes de Young, Bernstein y Bourdieu, desde el campo de la sociología de la educación, contribuyeron a hacer visibles las relaciones de poder incrustadas en el currículo escolar, dejando en evidencia cómo algunos grupos tienen el poder de seleccionar los contenidos curriculares de acuerdo a sus intereses, así como también la complicidad estructural que ha tenido la escuela en la reproducción de las desigualdades sociales. Como bien afirma Dubet "si no se ha logrado la igualdad de oportunidades, no es sólo porque la sociedad es desigual, sino también porque el juego escolar es más favorable para los más favorecidos" (2006, p. 15). 
El proceso de selección de contenidos, conocimientos, valores e ideologías que condensa el currículo, reafirmó posturas eurocéntricas y excluyó la diversidad étnica de los países, reforzando los relatos que presentaban a las sociedades nacionales como homogéneas. También se constituyó en el reflejo de la exclusión, el racismo epistémico y la desigualdad de género, contribuyendo a sostener las desigualdades étnicas raciales en las sociedades latinoamericanas.

A pesar del trascendente cambio que supuso, en las últimas décadas, el reconocimiento de derechos en varios países de la región, la situación de los pueblos afrodescendientes e indígenas continúa siendo problemática ya que estas sociedades siguen siendo generadoras de desigualdad y de racismo. Por ello, no es suficiente otorgarles visibilidad y reconocimiento a estos grupos si, paralelamente, no se transforman los discursos eurocéntricos y se combate el racismo estructural. Asistimos a un mundo hiperconectado y digitalizado que arrastra, al mismo tiempo, profundas asimetrías y desigualdades. Una de ellas es sin duda alguna el racismo, el cual se manifiesta en muchos lugares y del que, como bien sabemos, la escuela no sólo no está exenta, sino que contribuye a reproducirlo.

Las sociedades latinoamericanas han sido forjadas con una ideología racista, en nombre de la cual se establecieron jerarquías, configurando un orden racial con clara desventaja para los/as afrodescendientes. La glorificación de la identidad nacional blancomestiza y el mito de la democracia racial en América Latina contribuyeron a negar las raíces negras en los estados nacionales, al tiempo que construyeron la imagen del negro/a como alguien ajeno al progreso y a los valores de la ciudadanía moderna. De este modo, quedaron fuera del campo de visibilidad las desigualdades sociales derivadas del orden 44 | INTEREDU № 4 Vol. I (JULIO 2021) PÁGs. 41-68. ISSN: 2735-6523 
socio-racial para ser atribuidas a una característica propia "del negro/a". Es así como la ideología del mestizaje, en América Latina y en el Caribe, encubre y niega la existencia del racismo (Curiel, 2007). En consecuencia, "el mestizaje reconoce la presencia de poblaciones no identificadas con la blancura en Latinoamérica, pero reafirma la supremacía cultural, y a veces biológica, de herencias blancas hispánicas" (Reyes-Santos, 2008, p.7).

RACISMO EPISTÉMICO EN EL ENTRAMADO PEDAGÓGICO-CURRICULAR EN LA ARGENTINA

Todavía huelo la espuma del mar que me hicieron atravesar.

La noche, no puedo

recordarla. Ni el mismo océano podría

recordarla.

Pero no olvido el primer alcatraz que divisé.

Altas, las nubes, como inocentes testigos presenciales.

Acaso no he olvidado ni mi costa perdida, ni mi lengua ancestral

Me dejaron aquí y aquí he vivido.

Y aquí volví a nacer.

Nancy Morejón (1975)

El dominio colonial de Europa sobre América no sólo se apoyó en el sometimiento militar, el genocidio y el control de sus recursos. También supuso la instauración de ideas racistas que postulaba la superioridad natural de los europeos para justificar la explotación de otros pueblos y legitimar las desigualdades económicas y sociales. Este discurso convirtió al europeo en sujeto civilizador y a los otros pueblos en seres que debían ser dominados. El racismo entonces "es una ideología y una práctica material que postula la existencia de razas; las clasifica en superiores e inferiores, y les atribuye determinadas características intelectuales y morales. Esta ideología se manifiesta a través de prácticas sociales e INTEREDU № 4 VOL. I (JULIO 2021) PÁGS. 41-68. ISSN: 2735-6523| 45 
institucionales, y para el caso de los pueblos indígenas y afrodescendientes, se expresa en la vulneración sistemática de sus derechos fundamentales" (Ocoró y Mazabel, 2021, p. 26). En consecuencia, “(...) el racismo tiene una base más bien política, ideológica y cultural y no biológica, aunque su soporte principal siempre ha sido el cuerpo humano, el color de la piel, los rasgos y evidencias físicas" (Bello y Paixão, 2009, p. 42).

Aun cuando desde un punto de vista científico las razas no existen, no se puede negar que en la vida cotidiana representan una categoría social poderosa que domina el imaginario de identidad. Raza es un concepto moderno que empezó a tomar forma con el surgimiento de una economía mundial, en la cual la conquista de América, la creación de los imperios marítimos, y la esclavización de africanos constituyen pilares en su genealogía (Winant, 2000). Aun cuando es un lugar común asociar la raza al color de la piel, ésta sería una categoría de invención social producto de la modernidad que excede las elaboraciones teóricas planteadas y avaladas por el racismo científico del siglo XIX y comienzos del XX. Aun cuando las ideologías políticas fueron confrontadas y la ciencia proclamó la inutilidad de la asociación de raza y biología, el legado histórico de la raza como concepto se mantuvo. En realidad, se ha naturalizado hasta el punto de que muchas prácticas cotidianas, relaciones y oportunidades sociales se llegan a estructurarse en función de las apariencias fenotípicas. La raza tiene, en la práctica, efectos concretos ya que organiza las relaciones entre los individuos, incide en sus oportunidades sociales y es utilizada para justificar la discriminación y el racismo.

Esta matriz de pensamiento eurocéntrica es reproducida frecuentemente en nuestros sistemas educativos, configurando y sosteniendo el racismo epistémico. Como sistema de pensamiento 46 | INTEREDU № 4 VOL. I (JULIO 2021) PÁGs. 41-68. ISSN: 2735-6523 
histórico, el racismo epistémico subalterniza, inferioriza, oculta e invisibiliza otros conocimientos y saberes. Esta matriz epistémica y hegemónica desplaza, silencia y apaga otros sistemas de conocimiento y, en muchos casos, los combate con la pretensión de aniquilarlos. La hegemonía de los conocimientos eurocéntricos se impuso junto al despojo $\mathrm{y}$, en muchos casos, junto a la aniquilación de otros modos de conocer y de habitar el mundo. El racismo epistémico impone la superioridad de una cultura sobre otra, al punto de asimilarla, negarla o suprimirla (Ocoró, 2019). Tiene una estrecha relación con la primacía monocultural, hegemónica occidental, eurocentrista y científica, donde ciertos saberes, tradiciones y culturas han sido invisibilizados o inferiorizados. Este ha sido el caso de las epistemologías africanas, indígenas y afrodispóricas, que están ligadas a otros repertorios culturales, y en las que el saber y el conocimiento son inseparables del territorio y se funden con él. Estas son epistemologías holísticas, plurales, que entienden que la condición humana no puede reproducirse y mantenerse en equilibrio sin pensar en el territorio, y sin pensar en otros seres y ecosistemas que también lo habitan.

En Argentina, históricamente el currículo acompañó esa ideología que construía una representación subalterna y parcializada de todos aquellos que no descienden de europeos. Esta distinción entre seres superiores e inferiores, hecha con base en las tonalidades de la piel, ha servido para legitimar la opresión, contribuyendo a sostener el silenciamiento de la historia de los/as afrodescendientes en el currículo escolar. La historia de la población negra e indígena ha sido contada desde los ojos del relato oficial eurocéntrico y hegemónico. Los saberes escolares se orientaron a consolidar las identidades nacionales, silenciando y manteniendo en la subalternidad tanto la historia como la cultura de estas poblaciones. 
El trabajo de Ramallo (2017) analiza críticamente los Diseños Curriculares para la enseñanza de la Historia, en el marco de la Nueva Escuela Secundaria Argentina (NESA) del 2006, en la Provincia de Buenos Aires". El trabajo se propone rastrear "las presencias y las ausencias de la historia de África y los afrodescendientes" y, aunque estos diseños problematizan la centralidad de Europa en la historia mundial y recuperan algunos aspectos de la historia africana como la trata esclavista, como afirma Ramallo:

Los vínculos entre las culturas africanas y la identidad nacional (desde las producciones culturales hasta las diferentes presencias de afrodescendientes en nuestra región) continúan en una dimensión secreta e invisible. En el caso argentino (al intentar delimitarlo para compararlo con otros contextos, parecería que cuando se debe enseñar sobre las culturas africanas se lo hace únicamente para cuestionar la centralidad europea de la historia, en un intento de ampliar sus relatos con la variedad y multiplicidad de experiencias del mundo. De modo que las culturas africanas y afrodescendientes continúan apareciendo como un "otro", algo ajeno y desconectado de nuestra historia (Ramallo, p. 57).

La trata esclavista, como eje central de la presencia de la historia de África en los diseños curriculares, si bien es útil para cuestionar la hegemonía europea e inscribir estos procesos en relaciones de dominación y no de superioridad cultural, como comúnmente se hace, encapsula la historia de los pueblos africanos a sólo estos acontecimientos, instalando una representación que obstura la posibilidad de pensar otras

\footnotetext{
${ }^{1}$ Estos diseños fueron aprobados por Ley de Educación Provincial N¹3.688.
} 
nararrativas de la historia de estos pueblos. Como bien señala Pinheiro (2019):

Muy a menudo, el primer contacto que tienen los estudiantes en las escuelas con un cuerpo negro es en un barco tumbero, o esclavista como se les llama comúnmente. Este es el rasgo constitutivo fundamental de nuestra identidad ancestral. Aprendimos en la escuela que veníamos de "esclavos". Evidentemente, quien viene de "esclavos" no se siente privilegiado en su origen y construye una relación causal y psíquica directa que justifica su actual degradación social, su carencia de bienes materiales e inmateriales se justifica por su relación con su origen. Sin embargo, los negros no aparecieron en el mundo con esclavitud, al contrario de lo que nos enseñaron en las escuelas (Pinheiro, 2019, p. 331).

Estas narrativas también han estado presentes en los textos escolares. Estos no han sido neutros; muy por el contrario, han difundido una lectura eurocéntrica de la sociedad argentina en las que el desarrollo, los avances tecnológicos, la democracia y el conocimiento siguen siendo presentados como un atributo de hombres blancos, "civilizados". Contrariamente, los indígenas y afrodescendientes aparecen relegados de los imaginarios de desarrollo y de las actividades productivas (Ocoró, 2016). Estos pueblos han sido visibilizados como seres exóticos, conflictivos o salvajes (Soler, 2008) y de modo antagónico al nosotros nacional. A estos grupos, en general, no se los representa dentro de espacios de decisión, de progreso o de profesionalismo, sino que su presencia sólo es visibilizada cuando se menciona la esclavización, o en relación a problemas de desplazamiento, discriminación, pobreza y subdesarrollo, o por su desempeño en actividades deportivas, siempre por fuera de la historia nacional (Soler, 2008). 
En la lectura que los textos escolares hacen de la historia africana, esta pareciera ser solo la historia de la esclavización y la manera cómo estos pueblos fueron inferiorizados. De la opresión a la que fueron sometidos y de la continuidad del racismo y la discriminación, heredados de ese proceso, poco se habla (Ocoró, 2016). Hay silencios, miradas parciales o tergiversadas que borran la vida cultural, política y económica de estas poblaciones y sus aportes a la historia de la humanidad.

De acuerdo con Parra (2018), la utilización de los manuales escolares, en particular en el área de las Ciencias Sociales, permite plantear dos cuestiones:

Por un lado, convalidaron durante años el estatus de la conquista y la dominación, estableciendo como válido -e inevitable- el triunfo de las potencias europeas sobre los pueblos de América, Asia y África: su conquista, colonización y explotación. Por otro, modelaron en los alumnos una concepción lineal de la Historia que los alejó de un pensamiento crítico, así como del interés por plantearse el pasado y las fuentes históricas desde una mirada abierta que facilitara la formulación de dudas e interrogantes necesarios para avanzar en la investigación y construcción de nuevos aprendizajes desde un rol comprometido y participativo.

También debemos mencionar el papel reducido que tienen las poblaciones afrodescendientes en los textos escolares argentinos, ya que comúnmente estos solo aparecen en acontecimientos históricos puntuales como las invasiones inglesas, en el rol heroico de soldados que combatieron por la patria, o en algunos sucesos de las guerras de independencia (Cucuzza, 2007). También predomina la condición de vendedores ambulantes o sirvientes en el período colonial, desmereciendo otras actividades desarrolladas por estos (Balsas, 2011).

50 | INTEREDU № 4 VOL. I (JULIO 2021) PÁGs. 41-68. ISSN: 2735-6523 
Los estudios sobre estos manuales y sus contenidos permiten afirmar la existencia de un racismo epistémico que clausuró en el lugar del estereotipo y la subalternidad a las poblaciones y las culturas de origen africano. La historia escolar fue un medio muy poderoso para promover la idea de la supremacía racial blanca y reproducir la dominación cultural hacia estos grupos. La mayoría de los textos de uso escolar expresan el ideal eurocéntrico, ayudando a sostener el epistemicidio de los saberes y las historias de los grupos subalternos. Desafortunadamente, los textos escolares reproducen, legitiman y trasmiten valores e ideologías de los grupos dominantes (Apple, 1979).

El libro de texto ha ocupado un lugar muy importante en el sistema escolar, por cuanto se lo asume como la condensación del saber, la garantía de aprender contenidos, y como el currículo que la escuela desarrolla para que los/as chicos/as aprendan (Ocoró, 2016). En la actualidad, el COVID19 no sólo está desafiando el formato tradicional de los textos escolares, sino que el aula escolar hoy acontece a través de dispositivos tecnológicos. El texto escolar transita hacia nuevos formatos digitales en un contexto en el que, producto de las desigualdades educativas estrucutrales, no todos/as los/as alumnos/as logran sostener el vínculo pedagógico de la misma manera. Pensemos, por ejemplo, en las profundas barreras y desigualdades territoriales, culturales y digitales que existen en la región. Muchos estudiantes no tienen conexión a internet, especialmente en zonas rurales. Además, muchas veces, no cuentan en sus hogares con un espacio habilitado, ni con trayectorias familiares o capitales culturales que les ayuden a sostener estos nuevos formatos escolares. Esta coyuntura acentúa las históricas desventajas estructurales que afectan a las poblaciones afrodescendientes, tan castigadas por el racismo estructural; el mismo que desde hace largo tiempo convive en nuestras sociedades. 
EL CURRÍCULO COMO UN ESPACIO DE LUCHA EN AMÉRICA LATINA

Quien hoy transita por América Latina puede observar cómo los discursos que proclaman la libertad de mercado, la no intervención estatal, las privatizaciones - entre otros- y que fueron tan difundidos en los años 90, siguen latentes. Hoy los discursos conservadores y religiosos, de la mano de sus triunfos, buscan incidir en las políticas educativas y curriculares. En efecto, "el campo del currículum oficial está fuertemente condicionado por la lógica de la política, en la que las repercusiones mediáticas de las decisiones y la presencia de intereses partidistas tienen un peso decisivo" (García y Merchán 2003, p. 7).

En Brasil el movimiento "Una escuela sin partido", liderado por una ONG, ha presentado distintas iniciativas legislativas para controlar los contenidos curriculares. Bajo el argumento de que en la escuela debe existir neutralidad ideológica, política y religiosa, sostienen que "el profesor no es un educador" sino alguien que debe instruir, ya que los niños deben tener una "educación sin adoctrinamiento". Proponen también que los docentes no promuevan sus propias ideas políticas o partidarias en el aula y que no inciten a los alumnos a participar en manifestaciones o marchas. Además, invitan a los padres y estudiantes a denunciar el supuesto "acoso ideológico" de los profesores.

También podemos mencionar brevemente lo que ocurre en Colombia, donde las presiones de grupos evangélicos por contener la supuesta "ideología de género", o el "castrochavismo," vienen ganando un espacio en la sociedad. El "castrochavismo" es un término que se origina en el contexto político colombiano, por medio del cual los detractores del proceso de paz critican la participación política de las FARC y los acuerdos de paz. Sus defensores afirman que Colombia 
seguirá los pasos de Cuba y de Venezuela (Fidel Castro y Hugo Chávez), de ahí el nombre. Se trata de grupos conservadores de la derecha colombiana que agitan el mito de que Colombia corre el riesgo de entrar en el socialismo o en el comunismo, y de ser llevada a una crisis como la que enfrenta Venezuela. En esencia esta es una forma de atacar a otras visiones políticas.

En la Argentina, durante el gobierno del expresidente Macri (20152019) el Ministro de Educación y Deportes de la Nación, Esteban Bullrich, manifestó, durante una visita oficial a la Provincia de Salta: "en las escuelas públicas debe haber enseñanza de la religiosa" (Telam 24-42017). También podemos hacer mención a las declaraciones del Jefe de Ministros Marcos Peña durante el mismo gobierno, cuando en una entrevista expresó: “En la Argentina se piensa que ser crítico es ser inteligente, pero nosotros creemos que ser entusiasta y optimista es ser inteligente, y que el pensamiento crítico llevado al extremo, le ha hecho mucho daño a la Argentina" (Diario registrado 11-9-17).

Se trata de proyectos claramente ultraconservadores, que son parte de una alianza integrada por grupos empresariales, conservadores, religiosos, y por medios de comunicación hegemónicos, una alianza que va tomando fuerza en algunos países, y con mayor envergadura en Brasil, cuya envestida neoliberal irrumpió desde el golpe a la expresidenta Dilma Rousseff (2011-2016). Este discurso conservador y autoritario ataca la diversidad cultural, la pluralidad y todas las formas de expresión que se manifiestan a favor de la inclusión, la igualdad y la justicia para los sectores que menos tienen.

Bajo el paraguas de evitar "adoctrinamientos ideológicos", estos movimientos ultraconservadores quieren evitar que en la escuela se hable de problemas raciales, feminismo, igualdad de género, homofobia, entre otros temas. Esos sectores no sólo criminalizan las prácticas docentes, sino 
que proponen un currículo neutral y descontextualizado de la realidad. Es una visión ahistórica del currículo, en la cual se presupone que los contenidos se desarrollan al margen del contexto histórico que vive la sociedad y que disfraza de neutralidad su propia visión de mundo y de sociedad. Instalar una mirada punitiva sobre lo que se enseña, lo que se piensa y lo que se aprende en la escuela, sólo es una muestra del autoritarismo creciente que envuelve a la sociedad brasileña. El debate sobre los problemas y realidades que vive una sociedad debe estar presente en la escuela, porque de lo contrario esta institución estaría condenada al ostracismo.

Estamos ante un nuevo escenario donde actores conservadores, élites, derechas, pero también sectores de la sociedad civil que acompañan estos consensos, participan de la construcción de nuevos sentidos curriculares, tratando de imponer su propia interpretación de la sociedad y de construir hegemonía cultural. En este marco, toda manifestación, crítica y progresista, es censurada y tachada de ideología o populismo. Valga recordar que durante el siglo XIX en América Latina la escuela fue uno de los dispositivos más importantes para orientar la formación de futuros ciudadanos para la nación, al punto que variados sectores se disputaron su direccionalidad. En efecto, "tanto para la iglesia, los estados en proceso de conformación y los diversos sectores de la vida política e intelectual, la escuela se constituye en espacio privilegiado que posibilita y propicia el proceso de "formación del ciudadano". Unos desde un criterio moral; otros desde proyectos civilistas pero, en fin, bajo un principio común que los identifica: la población debe pasar por la escuela ya que ella es garantía de una lengua común, una identidad nacional, unos hábitos de comportamiento y una racionalidad determinadas" (Martínez y Narodowsky, 1996, p. 11). 
Lo antedicho pone en evidencia que el currículo escolar "está muy lejos de ser un factor neutro" (Goodson, 1991, p. 28); es más bien una construcción histórica que no puede verse al margen de los conflictos e intereses que acontecen en la sociedad. El currículo constituye, entonces, un espacio de lucha y es influenciado y moldeado en el marco de un contexto histórico; vale decir "no es el resultado de un proceso abstracto, ahistórico y objetivo, sino que es originado a partir de conflictos, compromisos y alianzas de movimientos y grupos sociales, académicos, políticos institucionales, etcétera, determinados" (Goodson, 1995, p.193).

Partiendo de lo que señala Lundgren "el concepto de currículo no se puede alcanzar sin un entendimiento de la interacción entre el texto y el contexto" (1992, p. 21). El contexto político, económico y discursivo en América Latina cambió. Hoy distintos actores pugnan por la construcción de nuevos sentidos en el campo educativo. Lejos de desterrar las luchas por el control de los saberes y aprendizajes, en América Latina asistimos a la irrupción de nuevas formas de control de los contenidos y saberes en la escuela, de la mano de discursos conservadores y religiosos. Es así que en el momento actual es ineludible pensar un currículo para la diversidad, no solo porque América Latina es una región con una diversidad étnica y cultural importante, sino porque en el presente, es cada vez más claro que las disputas políticas, las luchas y tensiones entre grupos sociales se plasman en el currículo.

\section{“LOS/AS AFroARgENTINOS/AS y DE LA CULTURA AFRO” EN LA AGENDA EDUCATIVA}

Argentina forma parte de los países que, aun contando con leyes antidiscriminatorias, no tiene una amplia legislación dirigida a los afrodescendientes. El Estado argentino, sin embargo, ha suscrito $y$ ratificado algunas convenciones internacionales específicas para la INTEREDU № 4 VOL. I(JULIO 2021) PÁGS. 41-68. ISSN: 2735-6523| 55 
cuestión étnica y racial. Además, algunas de ellas cuentan con rango constitucional desde 1994. La Constitución de 1994 le encomendó al Congreso la tarea de elevar a rango constitucional los tratados y convenios internacionales. En consecuencia, dichos tratados y convenios adquirieron un nivel superior a las leyes nacionales y provinciales. En el artículo 75 (inciso 22) se destacan, entre otros, la Declaración Universal de Derechos Humanos; la Convención para la Prevención y la Sanción del Delito de Genocidio; la Convención sobre la Eliminación de todas las Formas de Discriminación contra la Mujer; y la Convención Internacional sobre la Eliminación de todas las Formas de Discriminación Racial. Esta última condujo a través de la Ley № 24515 de 1995, a la creación del Instituto Nacional contra la Discriminación, la Xenofobia y el Racismo (INADI), cuyo objeto sería luchar contra todas las formas de discriminación.

Así mismo, la Reforma Constitucional de 1994 reconoció la preexistencia de las poblaciones indígenas a nivel nacional, a la vez que les garantizó derechos territoriales, educativos, y el respeto a su identidad étnica y cultural. La Ley Federal de Educación de 1993 instó a la creación de programas de educación intercultural bilingüe, y encomendó a la escuela a trabajar para la diversidad y el reconocimiento de los pueblos originarios, en clara alineación con los discursos multiculturales emergentes (Argentina, 1993). Es así como esta nueva narrativa de la diversidad se fue instalando en las políticas curriculares. A pesar de ello, la Constitución de 1994, no hizo ninguna referencia a los/las afrodescendientes. Será a partir del año 2010 cuando más claramente los afrodescendientes comienzan a formar parte de la agenda del Estado al ser incluidos en el Censo Nacional de Población de ese año. Una de las consecuencias del Censo de 2010, en el cual los afrodescendientes fueron incluidos por primera vez desde el siglo XIX, es la institucionalización de 56 | INTEREDU № 4 Vol. I (JULIO 2021) PÁGs. 41-68. ISSN: 2735-6523 
programas del Estado que los consideran como sujetos específicos de políticas públicas (Ocoró, 2015).

Podemos decir que el Estado argentino ha emprendido un camino hacia la visibilización de los/las afrodescendientes. En la actualidad, los/las integrantes de la comunidad afro han sido incluidos/as en distintos programas como sujetos de derechos. Aunque no son muchos los alcances de estas iniciativas, no dejan de ser significativos, especialmente en un país cuya política, históricamente, se caracterizó por excluir a esta comunidad. Si bien no se ha institucionalizado aún una agenda educativa antirracista en la Argentina, las nuevas retóricas que el Estado viene asumiendo, y los limitados avances legislativos, trastocan el paradigma homogeneizador que caracterizó la historia de la Argentina y, al mismo tiempo, habilitan nuevos canales para el reconocimiento histórico de la comunidad afrodescendiente.

La Ley 26.852 de 2013, promulgada el 20 mayo de 2013, establece el 08 de noviembre como "El Día Nacional de los/as Afroargentinos/as y de la Cultura Afro" en conmemoración a la fecha de fallecimiento de la afroargentina María Remedios del Valle. La Ley encomienda al Ministerio de Educación de la Nación que se incorpore dicha fecha al calendario escolar y promueva la cultura afro en los contenidos curriculares de todos los niveles del sistema educativo. También encomienda a la Secretaría de Cultura de la Nación la conmemoración de la fecha a través de políticas públicas orientadas a visibilizar y apoyar la cultura afro. La Ley 26.852 inaugura la inclusión de los afrodescendientes en la legislación nacional y en el ámbito escolar a través de las efemérides escolares. De todas maneras, falta avanzar en lo que respecta a la inclusión efectiva de la historia africana y afroargentina en el currículo escolar. La escuela es un espacio importante para problematizar el racismo que existe en la 
sociedad y, sobre todo, para contribuir a valorizar la historia africana y afroargentina.

Remedios del Valle fue apodada por los soldados como "La Madre de la Patria" por su incansable labor en los ejércitos. Esta heroína negra fue un personaje importante dentro de los acontecimientos de las luchas por la independencia. Además, se vinculó como combatiente al Ejército del Norte y, por su destacado desempeño, Manuel Belgrano la designó Capitana del Ejército.

La recuperación de la figura de María Remedios del Valle por parte del activismo afro se halla inmersa en la disputa por marcar nuevos significados culturales, nuevas representaciones y nuevos procesos simbólicos en esa argentinidad esquiva a la etnicidad y a la diversidad (Ocoró, 2019). La representación de una heroína negra tiene mucha fuerza simbólica, pues participa de la construcción de la patria y su figura pasa a formar parte de la memoria histórica nacional.

María Remedios del Valle es una figura importante para cuestionar los imaginarios de nación pensados por las elites locales y por las historias hegemónicas, pues es una capitana de la patria. No representa un soldado raso, sino que ingresa dentro de los personajes con rango dentro del ejército. Es además mujer, lo cual traza una distancia respecto a las figuras masculinas tradicionalmente involucradas en las efemérides afro en la región. Así, la reivindicación de María Remedios del Valle ha servido como punto de inflexión para que los afrodescendientes reinterpreten su historia y el papel que desempañaron en la construcción de la nación, entrando así, de esta manera, en la disputa por un lugar protagónico dentro de los héroes nacionales que históricamente les fue negado. La Argentina tiene ahora una madre de la patria y es de origen africano (Ocoró, 2019). 
En el año 2014, el Senado de la República Argentina, a través de la Resolución CFE No. 240/14, dispuso incorporar el Día Nacional de los/las Afro argentinos/as y de la Cultura Afro a las efemérides escolares (Argentina, 2014). El reto sería fortalecer una perspectiva intercultural que afiance la figura de María Remedios del Valle e instituya su efeméride en las prácticas y en el discurso escolar. A pesar de ello, esta Resolución, así como la Ley 26.852 de 2013, son de gran trascendencia para la población afrodescendiente y para la sociedad en su conjunto porque hacen de la escuela un espacio un poco más plural, que no es intrascendente si tenemos presente la existencia del racismo epistémico, el cual impone la superioridad de una cultura sobre otra, al punto de asimilarla, negarla o suprimirla (Ocoró, 2019).

Cabe mencionar dos propuestas que han sido gestadas recientemente. La primera de ellas surge por iniciativa de la Cátedra de UNESCO, Educación Superior y Pueblos Indígenas y Afrodescendientes de la Universidad Nacional de Tres de Febrero- UNTREF, dirigida por Daniel Mato, y de la cual participan un conjunto de Instituciones de Educación Superior y de líderes indígenas y afrodescendientes. Esta iniciativa impulsa la actualización de la Ley de Educación Superior (24.521) de 1995, con la intención de adecuar sus artículos a lo dispuesto en los incisos 17 y 22 del artículo 75 de la Constitución Nacional (Argentina, 1995). El argumento principal de esta propuesta es que la Ley vulnera los derechos de estas poblaciones ya que:

Incluye género y discapacidad, pero nada dice, sobre pueblos indígenas y afrodescendientes, y esto es discriminatorio, situación que ha sido observada y señalada para Argentina, las continuidades en las discriminaciones estructurales que existen en nuestro país, en particular para "pueblos indígenas (PI)" y comunidades 
afrodescendientes (Cátedra de UNESCO Educación Superior y Pueblos Indígenas y Afrodescendientes, 2021, p. 1).

La segunda iniciativa impulsada por el INADI, con la participación de un grupo de funcionarios/as del gobierno del presidente Alberto Fernández, es la creación de una "Comisión Nacional para el Reconocimiento Histórico de la Comunidad Afroargentina", la cual tiene como objetivo "contribuir al cumplimiento del pleno goce de derechos de los ciudadanos de la comunidad Afroargentina" (Ministerio de Derechos Humanos, 2020). Esta Comisión cuenta con la participación del Ministerio de Justicia y Derechos Humanos, el Ministerio de Educación, la Secretaría de Derechos Humanos y el Instituto Nacional contra la Discriminación, la Xenofobia y el Racismo (INADI). Si bien esta Comisión es reciente, y no alude en forma directa a cuestiones educativas, se propone "ampliar el trabajo realizado, en aspectos aún no abordados, brindando un punto focal al interior de la Administración Pública Nacional que atienda la especificidad de las demandas y propuestas de dicha comunidad". Ante este panorama, se espera que esta Comisión pueda proponer acciones encaminadas a ampliar el trabajo realizado en el campo educativo.

\section{HACÍA UN CURRÍCULO INTERCULTURAL EN LA EDUCACIÓN}

En los últimos años, la visión monocultural de la escuela y la visión del sujeto moderno como un ente homogéneo y universal han sido cuestionadas, al punto que la atención a la diversidad se ha convertido en un importante indicador de inclusión en la construcción de una sociedad democrática. Es así que la Agenda 2030, impulsada por la Cumbre del Desarrollo Sostenible (2015), incorpora la inclusión, la equidad y la diversidad cultural como objetivos estratégicos a trabajar en la educación 
con el fin de lograr un mundo sostenible en el año 2030. Esto implica valorar la importancia de todas las expresiones y grupos culturales que componen la sociedad, así como las diferentes cosmovisiones. Más aún, si tenemos en cuenta que vivimos en una región que es pluriétnica y pluricultural.

La masificación del acceso escolar ha desafiado a la escuela a trabajar con nuevos sujetos que ya no se corresponden con los tipificados por el perfil históricamente esperado (Dubet, 2005). Esta apertura supuso también el ingreso de nuevos sujetos y nuevas problemáticas que la escuela siempre "dejó en el afuera" y que ahora la "problematizan" y la "desestabilizan". No todos los niños y jóvenes que ingresan son "creyentes" del orden escolar (Dubet, 2000). Los docentes deben imprimir mayor esfuerzo para entrar en diálogo con estas generaciones y para lograr su motivación y permanencia en la escuela. Este contexto de mutaciones sociales y culturales requiere construir nuevos consensos y nuevos sentidos educativos.

Estas transformaciones también han postulado debates y críticas sobre la pertinencia del currículo tradicional, parcelado en rígidas disciplinas escolares, e interpelan a la escuela y sus propuestas curriculares para acompañar dichas transformaciones. Se requiere que el currículo permita dialogar con los enormes problemas y desafíos que enfrenta la humanidad y que, desde un lugar crítico, aporte herramientas para que los/as alumnos/as construyan alternativas de futuro en un mundo que está cambiando con gran celeridad.

Atender a las necesidades de un mundo plural, diverso e intercultural es una cuestión crucial para las sociedades latinoamericanas. Esto plantea el problema de la relación entre escuela, diversidad y equidad y nos conduce a preguntarnos ¿En qué medida las prácticas pedagógicas favorecen la inclusión y la diversidad en la escuela? ¿Puede 
la escuela de hoy dar respuesta a la diversidad de sujetos que la componen? ¿Cómo se tramita hoy en estos tiempos la diversidad en las escuelas? ¿Qué subjetividades han devenido producto de las transformaciones socio-culturales contemporáneas? ¿Qué prácticas se proponen para avanzar en el reconocimiento y la valoración de todas las identidades y grupos que componen nuestra América Latina? ¿Qué propuestas curriculares integran a las poblaciones indígenas, afrodescendientes, a los grupos diversos, entre otras? La escuela debe estar abierta a estos interrogantes y a la diversidad presente en nuestras sociedades. Hoy más que nunca en América Latina la escuela debe incluir en su agenda una lucha comprometida con la defensa de los valores democráticos y propiciar la participación y la democratización en su interior, para avanzar en la construcción de una sociedad más libre, justa y equitativa.

En una sociedad democrática, el currículo debe impulsar la reflexión sobre la vivencia de la diversidad y la interculturalidad desde una epistemología pluralista, como un medio para superar el eurocentrismo y la educación monocultural que históricamente han hecho parte de nuestras escuelas y universidades. Una política curricular plural acorde a los tiempos presentes, y a las realidades sociales $\mathrm{y}$ culturales de América Latina, tiene el desafío de incorporar a las culturas minoritarias y sus saberes en la producción de conocimiento, fomentando así su inclusión. No se trata sólo de garantizar derechos a las minorías étnicas, sino de avanzar hacia sociedades más equitativas y conscientes de su historia y de su diversidad. Se trata de que cada sociedad pueda servirse de los conocimientos y saberes de todos los grupos, para pensar su propio desarrollo y crear alternativas en pos de su presente y su futuro.

En definitiva, para avanzar en el desarrollo de políticas interculturales o en la interculturalización de la educación, es necesario 62 | INTEREDU № 4 VOL. I (JULIO 2021) PÁGs. 41-68. ISSN: 2735-6523 
someter a debate el discurso hegemónico eurocéntrico y las relaciones de poder mediante las cuales se han jerarquizado los saberes y los conocimientos de las comunidades indígenas y de los pueblos afrodescendientes. Si se pretende construir nuevas relaciones que recuperen y valoricen los conocimientos y saberes epistémicos de los pueblos negros e indígenas en América Latina, la descolonización epistémica es tarea obligada. No hay inclusión posible, no hay interculturalidad posible sin la confrontación de las epistemologías hegemónicas y sin la incorporación de las epistemes de los grupos subalternos.

No habrá "una escuela plural" mientras en el currículo, el análisis del racismo se diluya o se esquive mediante lecturas reduccionistas. No habrá "una escuela plural", mientras existan silencios históricos sobre los aportes de los afrodescendientes en la construcción de la nación y se refuerce el mito del mestizaje para acallar su identidad. No habrá "una escuela plural", mientras no se eliminen los estereotipos culturales y racistas con los que se representa a los afrodescendientes.

\section{CONSIDERACIONES FINALES}

La problematización del currículo es un requisito ineludible para construir una sociedad democrática. El currículo debe servir como una herramienta de apertura y de diálogo intercultural, para generar oportunidades igualitarias en la cotidianidad escolar. La escuela debe respetar las diferencias y valorizarlas, pero también debe contribuir a construir un "lugar común" en el que, más allá de nuestras diferencias, podamos comunicarnos y construir una sociedad plural. Es necesario que ese lugar "común" no sea un relato homogéneo, eurocéntrico, patriarcal, mono-cultural, como el que se planteó desde los inicios de la escuela moderna, sino que, partiendo de la inclusión de nuestras diferencias culturales, étnicas, religiosas, físicas, sexuales, entre otras, sirva para INTEREDU № 4 VOL. I (JULIO 2021) PÁGs. 41-68. ISSN: 2735-6523| 63 
construir nuevos consensos. Por supuesto se trata de consensos y no de cierres totales y definitivos. Será tarea de todos articular la construcción de una cultura en común que vertebre la vida escolar.

Es importante trabajar por una escuela que permita la expresión de todas las voces y de todos los actores de la historia; una escuela que marque una ruptura con el mandato de homogenización que le fuera encomendado y que acompañe, desde los contenidos curriculares, las prácticas educativas y la formación docente, al igual que la construcción discursiva de un nuevo proyecto educativo intercultural y antirracista que reconozca e incorpore los aportes de los/as afrodescendientes a la historia y a la vida presente.

\section{REFERENCIAS}

Apple, M. (1979). Ideología y currículo. Barcelona: Akal.

Balsas, M. (2011). Negritud e identidad nacional en los libros escolares argentinos: Del surgimiento del sistema nacional de educación al bicentenario. Estudios Sociológicos, 29(86), 649- 686.

Bello, Á. y PaixÃo, M. (2009). Una mirada a la situación de los derechos de los afrodescendientes en América Latina. En: Afrodescendientes en América Latina y el Caribe: Del reconocimiento estadístico a la realización de derechos. Serie población y Desarrollo 87. Santiago de Chile: CEPAL, 2009. LC/L.3045-, 39-85.

Bonilla, Silva, E. (2011). ¿Qué es el racismo? Hacia una interpretación estructural. En: debates sobre ciudadanía y políticas raciales en las Américas Negras. Universidad Nacional de Colombia y Universidad del Valle, editores, 649-698.

Bourdieu, P. y Passeron J. (2003). Los herederos: Los estudiantes y la cultura. Buenos Aires: Siglo Veintiuno Editores Argentina. 
Cucuzza, R. (2007). Yo argentino: la construcción de la nación en los libros escolares (1873-1930). Buenos Aires: Miño y Dávila.

Curiel, O. (2007). Crítica poscolonial desde las prácticas políticas del feminismo antirracista". En: Nómadas (26), 92-101.

Domenech, E. (2006). Etnicidad e inmigración: ¿hacia nuevos modos de integración en el espacio escolar? Astrolabio. Revista Virtual del Centro de Estudios Avanzado de la Universidad Nacional de Córdoba, (4).

Dubet, F. (2006). Mientras más desigual es la sociedad más desigual es la escuela. Revista Docencia, 29, 40-45.

Dubet, F. (2005). ¿Mutaciones institucionales y/o Neoliberalismo?. Conferencia inaugural del Seminario Internacional sobre "Gobernabilidad de los sistemas educativos en América Latina" organizado por el IIPE/UNESCO en Buenos Aires, 24 y 25 de noviembre. Revista colombiana de Sociología. p. 63-80.

Finocchio, S. (2012). América Latina: nuevos rumbos en los saberes educativos. Boletín de la Biblioteca del Congreso de la Nación, 126. 2012. p.103-115. Buenos Aires.

Fraser, N. (2000). ¿De la redistribución al reconocimiento? In: New Left Review № 0. Edición en español. Londres, Inglaterra. 2000. p. 7-23.

García Pérez, F.F. y Merchán, F.J. (2003). La construcción de la identidad nacional en las escuelas de Andalucía. SEANCE n²: "École et nation". La "diversité", la pluralité identitaire et l'école. 2013, p. 207-215. Disponible en https://idus.us.es/xmlui/bitstream/handle/11441/25488/La_construc cion_de_la_identidad_nacional.pdf?sequence=1. Acceso en 02 de febrero de 2018.

Goodson, I. (1995). Historia del currículum: la construcción social de las disciplinas escolares. Barcelona: Pomares-Corredor. 
Goodson, I. F. (1991). La construcción social del currículo. Posibilidades y ámbitos de investigación de la historia del currículo. Revista de Educación, 1991, p. 7-37.

Lundgren U.P. (1992). Teoría del Curriculum y escolarización, Madrid, Ediciones Morata, 1992.

Martínez Boom. A y Narodowski, M (comps.). (1997). Escuela, historia y poder, miradas desde América Latina, Buenos Aires, Ediciones Novedades Educativas.

Ministerio de Derechos Humanos (9 de noviembre de 2020). Comisión Nacional para el Reconocimiento Histórico de la Comunidad Afroargentina.https://www.argentina.gob.ar/noticias/comisionnacional-para-el-reconocimiento-historico-de-la-comunidadafroargentina.

Morejón, Nancy. (2003). Looking within/Mirar adentro. Selected Poems/Poemas escogidos, 1954-2000. Edited and with an Introduction by Juanamaria Cordones-Cook. Series: African American Life Series.Wayne State University Press. Detroit.

Morejón, N. (1975). “Mujer Negra”. Casa de las Américas, № 88, 119-20.

Ocoró Loango, A, y Ocoró, Loango A. (2010). Afroargentinidad y memoria histórica: La negritud en los actos escolares del 25 de mayo. (Tesis de Maestría, Faculdad Latinoameticana de Ciencias Sociales, Argetina). Disponible en: http://www.flacsoandes.org/dspace/handle/10469/2997.

Ocoró, Loango A. (2015). Los afrodescendientes en Argentina: la irrupción de un nuevo actor en la agenda política y educativa del país. Revista Colombiana de Educación, (pp. 137-157). Colombia, [S. 1.](69). Disponible en: https://revistas.pedagogica.edu.co/index.php/RCE/article/view/328 .doi:10.17227/01203916.69rce137.157

66 | INTEREDU № 4 VOL. I (JULIO 2021) PÁGs. 41-68. ISSN: 2735-6523 
Ocoró Loango, A. (2016). La nación, la escuela y "los otros": reflexiones sobre la historia de la educación en Argentina y Colombia en el imaginario civilizatorio moderno. Nodos y Nudos, 5 (41), 35-46.

Ocoró, Loango A. (2019). Del soldado raso a la capitana de la patria: Un aporte para repensar los feminismos negros desde la Argentina. In A. Lafontaine; A. Castro; B. Reiter; C. Nazareno; C. Miranda; G. De Laforcade; et al. (AA.) \& A. Ocoró; R. Septien. (Eds.), Afrodescendencias y contrahegemonías: Desafiando al decenio, (pp. 157-180) CLACSO. doi:10.2307/j.ctvt6rm7b.8

Ocoró Loango, A., \& Mazabel, M. (2021). Racismo en la educación superior: un análisis desde la perspectiva de los pueblos indígenas y afrodescendientes en Colombia. Universidades, 72(87), 15-33. https://doi.org/10.36888/udual.universidades.2021.87.521

Oliveira, D. (2001). Racismo estructural, apuntes para la discusión conceptual. In I. León (Ed.), Agencia latinoamericana de información. Disponible en: http://www.alainet.org/publica/cmrx/racismoestruc.html

Parra, J.L. (2018). La visión eurocéntrica sobre la historia y la cultura de los pueblos conquistadosLa ciencia como soporte de la dominación. Margen: revista de trabajo social y ciencias sociales, №. 88, 1-25.

Pinheiro, B. (2019). Educação em Ciências na Escola Democrática e as Relações Étnico-Raciais. Revista Brasileira de Pesquisa em Educação em Ciências, n. 19, p. 329-344, 2019.

Ramallo F. (2017). Normativas insurgentes y descolonización de la educación: notas desde la enseñanza de la historia de África y los afrodescendientes en el contexto bonaerense. Pasado Abierto. Revista del CEHis. №6. Mar del Plata. Julio-Diciembre.

Segato, R. (1998). Alteridades históricas/Identidades políticas: una crítica a las certezas del pluralismo global. Serie Antropología, (234), 2-28. Universidad de Brasilia. 
Soler, C. (2008). Pensar la relación análisis crítico del discurso y educación. El caso de la representación de indígenas y afrodescendientes en los manuales escolares de ciencias sociales en Colombia. Discurso $\mathcal{E}$ Sociedad, 2(3), 642-678.

Reyes-Santos, I. (2008). Capital neoliberal, raza, migración: Análisis comparativo de relaciones domínico-haitianas y domínicopuertorriqueñas. En: Revue européenne des migrations internationales. En línea: http://remi.revues.org/4245. vol. 24 - n¹, 13-34. Acceso, febrero 02 de 2018.

Young, Michael F. D. (ed.). (1971). Knowledge and control: new directions for the sociology of education. London: Collier Macmillan.

Young, M, F. D. (2010). Why educators must differentiate knowledge from experience? Journal of the Pacific Circle Consortium for Education, v. 22, n. 1, p. 9-20. 